\title{
Maternal nutrition in early-mid gestation and placental size in sheep
}

\author{
Lynne Clarke ${ }^{1}$, Lindsay Heasman ${ }^{3}$, Darren T. Juniper ${ }^{2}$ and Michael E. Symonds ${ }^{3 *}$ \\ ${ }^{1}$ School of Animal and Microbial Sciences and ${ }^{2}$ Department of Agriculture, University of Reading, Whiteknights, \\ Reading RG6 6AJ, UK \\ ${ }^{3}$ Department of Child Health, University Hospital, Queen's Medical School, Nottingham NG7 2UH, UK
}

(Received 25 June 1997 - Revised 13 October 1997 - Accepted 14 October 1997)

\begin{abstract}
We investigated the influence of restricted maternal nutrition between 30 and $80 \mathrm{~d}$ gestation on placental growth. Singleton-bearing ewes were fed on either 0.6 (i.e. nutrient restricted) times their energy requirements or 2.25 times this amount (i.e. controls) up to $80 \mathrm{~d}$ gestation, when their placentas and fetuses were sampled and analysed. Nutrient-restricted ewes lost body condition score but not body weight and had lower plasma thyroid hormone concentrations than controls, but there were no differences in plasma glucose, non-esterified fatty acids or 3hydroxybutyrate concentrations between groups. There was no effect of maternal nutrient restriction on fetal weight, conformation or organ weights with the exception of brain weight which was lower in nutrient-restricted ewes. Nutrient restriction had no effect on total placental weight, or proportion of inverted placentomes, but was associated with an increased abundance of small placentomes and decreased weight of the fetal but not maternal components of the placenta. Fetal cotyledons from nutrient-restricted ewes also had a lower DNA but higher haemoglobin concentration than those sampled from controls. The plasma concentration of triiodothyronine in umbilical cord plasma was also increased in fetuses from nutrient-restricted ewes. In conclusion, maternal nutrient restriction during early-mid gestation is associated with a smaller placenta.
\end{abstract}

Placenta: Pregnancy: Sheep

In many species, a primary factor determining size at birth is placental weight which normally peaks by mid-gestation in sheep (Schneider, 1996). The major impact of placental growth on fetal weight in sheep has been clearly demonstrated using the technique of carunclectomy (Owens et al. 1995). This experimental manipulation can result in growth-retarded fetuses whose viability after birth is reduced (Harding et al. 1985). Similarly when ewes with a low body weight at conception lose body condition, but not weight, between 30 and $90 \mathrm{~d}$ of gestation, this is associated with both a small placenta and smaller lambs that are at increased risk from hypothermia (Clarke et al. 1997). It has, therefore, been proposed that a reduction in nutrient intake in early and mid-gestation can act to significantly restrict placental growth for which maximal proliferative growth occurs between 50 and $60 \mathrm{~d}$ gestation (Ehrhardt \& Bell, 1995).

Nutrient restriction not only reduces the energy available for growth of the conceptus but results in a reduced abundance of anabolic hormones in the maternal circulation (Bauer et al, 1995). This includes thyroid hormones for which the quantity and energy content of food consumed is a major factor determining plasma concentrations in both non-pregnant and pregnant individuals (Dauncey, 1990; Symonds, 1995). A reduced plasma concentration of maternal thyroid hormones could have an important influence on placental development as they can stimulate production of a number of placental hormones necessary for normal growth (Maruo et al. 1991). It has yet to be established if altered maternal nutrition, thyroid status and placental development are related. The following study therefore examined the hypothesis that maternal nutrient restriction between 30 and $80 \mathrm{~d}$ gestation would restrict placental size in association with altered maternal plasma thyroid hormone concentrations. This study was conducted using singleton-bearing ewes that were all of a normal body weight and condition in order to minimize any contrasting influences of fetal number or maternal size on placental development (Robinson et al. 1977, 1994). 


\section{Methods}

\section{Animals and diet}

Ten Welsh Mountain ewes of similar age and of known mating date were entered into the study. Ewes were grouphoused at $30 \mathrm{~d}$ gestation and were fed daily at 09.00 hours, either at 0.6 (i.e. nutrient restricted) times their maintenance energy requirements for $30-80 \mathrm{~d}$ gestation with respect to ewe body weight or at 2.25 times this level of feed (i.e. controls). Ewes were randomly allocated to either feeding group. All ewes were confirmed as bearing single fetuses by ultrasound scanning $42 \mathrm{~d}$ after mating and were then individually housed in pens for the remainder of the study. The amount of feed given to each ewe was increased at 45,60 and $74 \mathrm{~d}$ gestation in order to meet the higher energy requirements associated with growth of the cenceptus (Agricultural and Food Research Council, Technical Committee on Responses to Nutrients, 1992). Examples of the maintenance metabolizable energy (ME) requirements for a $40 \mathrm{~kg}$ single bearing ewe at $30,45,60$ and $74 \mathrm{~d}$ of gestation are $5.62,5.73,5.91$ and $6.22 \mathrm{MJ} / \mathrm{d}$ respectively. The diet comprised chopped hay that had an estimated ME content of $7.91 \mathrm{MJ} / \mathrm{kg} \mathrm{DM}$ and a protein content of $69 \mathrm{~g} / \mathrm{kg} \mathrm{DM}$ and barley-based concentrate that had an estimated ME content of $11.6 \mathrm{MJ} / \mathrm{kg} \mathrm{DM}$ and a protein content of $162 \mathrm{~g} / \mathrm{kg}$ DM. All diets contained adequate minerals and vitamins. The amount given each day to nutrient-restricted ewes was 420 (SE 50) g hay plus 95 (SE 13) g concentrate between 30 and $44 \mathrm{~d}$ gestation, 435 (SE 50) g hay plus 101 (SE 11) g concentrate between 45 and $59 \mathrm{~d}$ gestation, 450 (SE 50) g hay plus 106 (SE 11) g concentrate between 60 and $73 \mathrm{~d}$ gestation and 465 (SE 50) g hay plus 111 (SE I1) g concentrate between 74 and $80 \mathrm{~d}$ gestation. Control ewes were given daily 935 (SE 68) g hay plus 215 (SE 15) g concentrate between 30 and 44 d gestation, 950 (SE 68) g hay plus 220 (SE 15) g concentrate between 45 and 59 d gestation, 965 (SE 68) g hay plus 229 (SE 13) g concentrate between 60 and $73 \mathrm{~d}$ gestation and 980 (SE 68) $\mathrm{g}$ hay plus 234 (SE 13) g concentrate between 74 and $80 \mathrm{~d}$ gestation. Body condition score was assessed by the physical characteristics in the lumbar region, on and around the backbone and in the loin area immediately behind the first rib as described by Russel et al. (1969).

\section{Experimental design}

At $59 \mathrm{~d}$ gestation a jugular vein catheter was inserted into each ewe and the following day blood samples were taken at $1 \mathrm{~h}$ intervals between 08.30 and 15.30 hours, and the plasma collected and stored at $-20^{\circ}$. At $80 \mathrm{~d}$ gestation jugular vein blood samples were taken and each ewe killed with a lethal injection of barbiturate $(100 \mathrm{mg} / \mathrm{kg}$ pentobarbital sodium: Euthatal; RMB Animal Health, Stoke on Trent, Staffs., UK). Fetuses were then removed from the uterus and an umbilical cord blood sample immediately taken. This was followed by removal of the uterus, followed by classification, dissection and weighing of each individual placentome. The gross morphology of placentomes was characterized in terms of inversion or apparent overgrowth of fetal tissue within the placentome, according to that described by Vatnick et al. (1991), with inverted placentomes being classified $\mathrm{A}$ and everted placentomes $\mathrm{B}, \mathrm{C}$ or $\mathrm{D}$, depending on the extent of eversion. In addition, because of the striking difference in the appearance of the fetal and maternal components of each placentome it is possible to separate physically these components into fetal cotyledons and maternal caruncles (Alexander, 1964). There was no evidence of embryo mortality in any ewes. Samples of these tissues were frozen at $-70^{\circ}$ for subsequent analysis. All operative procedures and experimental protocols had the required Home Office approval as designated by the Animals (Scientific Procedures) Act of 1986.

\section{Laboratory procedures}

A known weight of fetal cotyledon or maternal caruncle was homogenized in $0.25 \mathrm{M}-\mathrm{NaOH}$ to a concentration of $250 \mathrm{mg} / \mathrm{ml}$. Following dilution of these samples, protein content was measured using the method of Lowry et al. (1951) using a standard curve $(50-250 \mu \mathrm{g} / \mathrm{ml})$ of bovine serum albumin (Sigma Chemical Co., Poole, Dorset, UK) for which intra- and inter-assay CV were 2.3 and $4.4 \%$ (n 5). For DNA and haemoglobin analysis the homogenate was neutralized with an equal volume of $0.25 \mathrm{M}-\mathrm{HNO}_{3}$ and diluted further with deionized water. The DNA concentration was analysed fluorometrically (Hinegardner, 1971) using a standard curve $(2.5-20 \mu \mathrm{g} / \mathrm{ml})$ made up from DNA-type 1 sodium salt 'highly polymerized' from calf thymus (Sigma Chemical Co.) for which intra- and interassay CV were 2.5 and $3.9 \%$. Haemoglobin content was determined by the cyanmethaemoglobin method using the Boehringer Mannheim test kit (no. 127 7429, Boehringer Mannheim, France) for which the intra- and inter-assay CV were 3.5 and $6.9 \%$. As the majority of placentomes were A-type for all ewes the results presented are for this category of placentome only. Plasma concentrations of glucose, non-esterified fatty acids (NEFA) and 3-hydroxybutyrate were measured enzymically as described by Symonds et al. (1986), whilst total triiodothyronine $\left(\mathrm{T}_{3}\right)$ and thyroxine $\left(\mathrm{T}_{4}\right)$ were measured using radioimmunoassays as described by Clarke et al. (1994). Due to the similarity of results obtained from maternal blood at sampling at 60 and $80 \mathrm{~d}$ gestation, results are only given for $60 \mathrm{~d}$ gestation.

\section{Statistical analysis}

Statistical analysis of the effect of maternal nutrition was assessed using a general linear model procedure for ANOVA.

\section{Results}

Ewe body weight, condition score and metabolic status

Irrespective of dietary regimen, ewe body weight remained similar in all groups between 30 and $80 \mathrm{~d}$ gestation, although body condition score declined over this period in nutrient-restricted ewes (Table 1). As expected both feed and estimated ME intakes were lower in the nutrient- 
Table 1. Maternal body weight, body condition score and food intake $\dagger$ in control and nutrient-restricted ewes

(Values are means with their standard errors)

\begin{tabular}{|c|c|c|c|c|}
\hline & \multicolumn{2}{|c|}{ Control ( $n 5)$} & \multicolumn{2}{|c|}{ Nutrient restricted $(n 5)$} \\
\hline & Mean & SE & Mean & SE \\
\hline \multicolumn{5}{|l|}{ Body weight (kg) } \\
\hline $30 \mathrm{~d}$ & 41.4 & 2.7 & 38.7 & 1.6 \\
\hline $80 \mathrm{~d}$ & 43.0 & 2.8 & 41.2 & 1.4 \\
\hline \multicolumn{5}{|l|}{ Body condition score $\ddagger$} \\
\hline $30 \mathrm{~d}$ & 2.6 & 0.3 & 2.7 & 0.2 \\
\hline $80 \mathrm{~d}$ & $2 \cdot 4$ & 0.3 & $1.5^{\star}$ & 0.1 \\
\hline Concentrate intake $(\mathrm{g} / \mathrm{d})$ & 216 & 9 & $104^{* * *}$ & 6 \\
\hline Hay intake $(\mathrm{g} / \mathrm{d})$ & 614 & 54 & $381^{\star \star}$ & 12 \\
\hline Calculated ME intake $(\mathrm{MJ} / \mathrm{d})$ & 6.49 & 0.35 & $3 \cdot 71^{\star \star \star}$ & 0.08 \\
\hline
\end{tabular}

ME, metabolizable energy.

Mean values were significantly different from those for controls, ${ }^{\star} P<0.05,{ }^{\star \star} P<0.01,{ }^{\star \star \star} P<0.001$ (ANOVA).

$\dagger$ Individual food intakes only measured between 42 and $80 \mathrm{~d}$ gestation.

$\ddagger$ Assessed as described by Russel et al. (1969).

restricted group compared with controls. At 60 d gestation there were no differences between groups in plasma glucose (controls: 5.69 (SE 0.47 ) mmol/l, $n$ 5; nutrient restricted: 5.02 (SE 0.29) mmol/l, $n$ 5), NEFA (controls: 0.54 (SE 0.13 ) mmol/l, $n$ 5; nutrient restricted: 0.65 (SE 0.10 ) $\mathrm{mmol} / 1, n 5$ ), or 3-hydroxybutyrate concentrations (controls: 0.33 (SE 0.04) mmol/l, $n$ 5; nutrient restricted: 0.25 (SE 0.05 ) $\mathrm{mmol} / 1, n 5$ ), but $\mathrm{T}_{3}$ (controls: 3.20 (SE 0.37 ) nmol/l, $n$ 5; nutrient restricted: 2.08 (SE 0.09) nmol/1, $n 5$, $P<0.05$ ), and $\mathrm{T}_{4}$ concentrations (controls: 84 (SE 8) nmol/1, $n$ 5; nutrient restricted: 58 (SE 9) $\mathrm{mmol} / 1, n 5$, $P<0.05$ ), were lower in the nutrient-restricted group.

\section{Placental and fetal weights and composition}

Total placental and fetal weight, and fetal : placental weight ratio were not influenced by nutrient restriction, although the total weight of fetal cotyledons but not maternal caruncles was lower in the nutrient-restricted group (Table 2). Nutrient-restricted ewes possessed more small placentomes (Fig. 1) and mean placentome weight was lower in this group (controls: 10.2 (SE 0.10) g, $n$ 5; nutrient restricted: $6.1(\mathrm{SE} 0.13) \mathrm{g}, n 5, P<0.05)$. There was no effect of nutrient restriction on the number of inverted placentomes. They were predominantly A-type in all ewes (type A: controls: 85.6 (SE 4.5) \%, $n$ 5; nutrient-restricted:
81.0 (SE 5.5) \%, $n$ 5; type B: controls: 12.8 (SE 4.3) \%, $n$ 5; nutrient-restricted: 16.2 (SE $5 \cdot 1$ ) \%, $n$ 5; type C: controls: 0.4 (SE 0.4) \%, $n$ 5; nutrient-restricted: 1.6 (SE 1.2) \%, $n$; type D: controls: 1.2 (SE 1.2$) \%, n 5$; nutrient-restricted: 1.0 (SE 0.4$) \%, n$ 5). Fetal conformation, i.e, girth (controls: 207 (SE 9) mm, n 5; nutrient-restricted: 209 (SE 3) mm, $n$ 5), crown-rump (controls: 135 (SE 12) mm, $n$ 5; nutrientrestricted: 140 (SE 5) $\mathrm{mm}, n$ 5), and limb length (controls: 131 (SE 6) mm, $n$ 5; nutrient-restricted: 130 (SE 9) mm, $n 5$ ), and weights of all major organs weighed i.e. liver (controls: 21.2 (SE 3.1) g, $n$ 5; nutrient-restricted: 17.5 (SE 0.8) g, $n$ 5), lungs (controls: 16.7 (SE 1.8) g, $n$; nutrient-restricted: 15.6 (SE 1-3) g, $n$ 5), kidney (controls: 3.1 (SE 0.6) g, $n$ 5; nutrient-restricted: 3.5 (SE 0.1) g, $n$ 5), and heart (controls: 2.6 (SE 0.3 ) g, $n$ 5; nutrient-restricted: 2.9 (SE 0.3 ) g, $n$ 5), with the exception of brain weight (controls: 9.1 (SE 0.8) g, $n$ 5; nutrient-restricted: 7.0 (SE 0.8 ) g, $n 5, P<0.05$ ) were similar between groups.

There was no difference in protein content of caruncles or cotyledons between groups, but DNA content of cotyledons was greatly reduced in the nutrient-restricted group compared with controls (Table 3). In contrast the cotyledonary haemoglobin content was lower in controls compared with nutrient-restricted ewes. There were no differences in the glucose (controls: 0.46 (SE 0.12) mmol/1, $n$ 5; nutrient-restricted: 0.35 (SE 0.07$) \mathrm{mmol} / 1, n$ 5), NEFA

Table 2. Placental and fetal weights at $80 \mathrm{~d}$ gestation in control and nutrient-restricted ewes

(Values are means with their standard errors)

\begin{tabular}{|c|c|c|c|c|}
\hline & \multicolumn{2}{|c|}{ Control ( $n 5)$} & \multicolumn{2}{|c|}{ Nutrient restricted $(n 5)$} \\
\hline & Mean & SE & Mean & $\overline{\text { SE }}$ \\
\hline Total placenta $(\mathrm{g})$ & 550.5 & 67.7 & 463.9 & 41.5 \\
\hline Maternal caruncles $(\mathrm{g})$ & 188.2 & 34.7 & 238.0 & 36.8 \\
\hline Fetal cotyledons $(\mathrm{g})$ & 362.4 & 38.8 & $266 \cdot 0^{*}$ & 21.2 \\
\hline Cotyledon number & 60 & 13 & $76^{\star *}$ & 4 \\
\hline Fetal weight $(\mathrm{g})$ & 362.8 & 8.9 & $314 \cdot 3$ & 26.7 \\
\hline Fetal weight/placental weight & 0.72 & 0.14 & 0.70 & 0.10 \\
\hline
\end{tabular}

Mean values were significantly different from those for controls, ${ }^{*} P<0.05,{ }^{\star \star} P<0.01$ (ANOVA) 


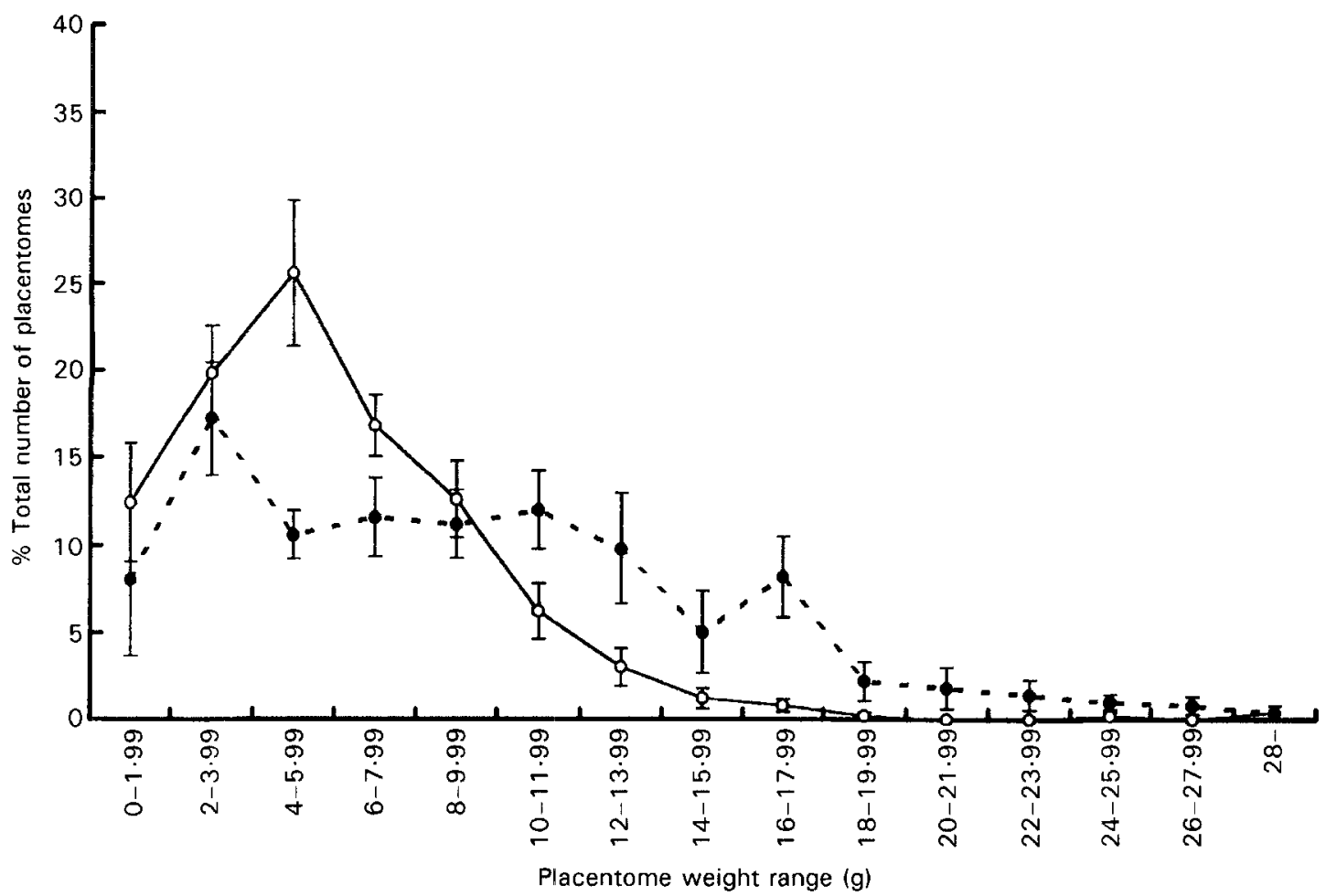

Fig. 1. Distribution of weights of individual placentomes in nutrient-restricted $(O ; n 5)$ and control $(\bullet ; n 5)$ ewes at $80 \mathrm{~d}$ gestation. Values are means with their standard errors represented by vertical bars. For details of diets, see p. 360 .

Table 3. Placental composition at $80 \mathrm{~d}$ gestation in control and nutrient-restricted ewes

(Values are means with their standard errors)

\begin{tabular}{|c|c|c|c|c|}
\hline & \multicolumn{2}{|c|}{ Control (n 5) } & \multicolumn{2}{|c|}{$\begin{array}{c}\text { Nutrient restricted } \\
(n 5)\end{array}$} \\
\hline & Mean & SE & Mean & SE \\
\hline \multicolumn{5}{|l|}{ Protein $(\mathrm{mg} / \mathrm{g})$} \\
\hline Maternal caruncles & 33 & 8 & 35 & 7 \\
\hline $\begin{array}{l}\text { Fetal cotyledons } \\
\text { DNA }(\mathrm{mg} / \mathrm{g})\end{array}$ & 26 & 5 & 31 & 6 \\
\hline Maternal caruncles & 0.3 & 0.2 & 0.2 & 0.1 \\
\hline Fetal cotyledons & $1 \cdot 2$ & 0.2 & $0.1^{\star}$ & 0.1 \\
\hline \multicolumn{5}{|l|}{ Haemoglobin $(\mathrm{mg} / \mathrm{g})$} \\
\hline Maternal caruncles & 3.6 & 1.8 & 4.5 & 0.9 \\
\hline Fetal cotyledons & 0.8 & 0.1 & $4.0^{*}$ & 0.6 \\
\hline
\end{tabular}

Mean values were significantly different from those for those for controls, ${ }^{*} P<0.05$ (ANOVA).

(controls: 0.13 (SE 0.01) mmol/1, $n$ 5; nutrient-restricted: 0.20 (SE 0.05 ) mmol $/ 1, n 5$ ), or $\mathrm{T}_{4}$ concentrations (controls: 43 (SE 5) nmol/l, $n$ 5; nutrient-restricted: 34 (SE 3) nmol/l, $n 5$ ) in umbilical cord plasma between groups, but $\mathrm{T}_{3}$ levels were higher in the nutrient-restricted group (controls: 0.39 (SE 0.04) nmol/1, $n$ 5; nutrient-restricted: 0.58 (SE 0.03) $\mathrm{nmol} / 1, n 5, P<0.05)$.

\section{Discussion}

\section{Nutrient restriction and placental development}

The present study's major finding is that maternal nutrient restriction between 30 and $80 \mathrm{~d}$ gestation had a significant effect on maternal plasma thyroid hormones and placental development without any immediate effects on fetal weight or conformation. It is established that feeding only half the calculated energy requirements at the time of mating can limit fertility (Robinson, 1990), so in order to avoid any compounding effects of maternal nutrition on embryo implantation, nutrient restriction was not commenced until $30 \mathrm{~d}$ after mating. It is established that placental growth is most rapid between 40 and 80 d gestation (Ehrhardt \& Bell, 1995) after which stage placental mass gradually decreases up to term (Schneider, 1996). Feeding ewes close to half of their energy requirements from 30 to $80 \mathrm{~d}$ gestation therefore limited the expected increase in placental mass by restricting the increase in individual placentome size, rather than affecting the magnitude of placentome eversion. Interestingly maternal nutrient restriction only limited growth of the fetal component of the placenta despite an increased abundance of placentomes. This conclusion is based on results obtained following physical separation of the fetal and maternal components of each placentome. It is recognized that this procedure does not give a definitive value regarding the weight of fetal tissue within each placentome, due to tissue contamination between each component, but does enable the same measurement to be made on all placentomes, which is not feasible using morphometry. Analysis of the fetal cotyledons and maternal caruncles for DNA and protein concentration gives an insight into differences in the number and tissue mass of placental nuclei, rather then cell size and number, due to the presence of binucleate cells, and syncytial tissue (Ehrdhart \& Bell, 1995). Fetal cotyledons in nutrientrestricted ewes were characterized as possessing far less 
DNA than those sampled from controls, and in the absence of any difference in protein content this is indicative of fewer placental nuclei with more tissue per nucleus. Nutrient-restricted ewes were also characterized as possessing cotyledons with a higher haemoglobin content, that is indicative of a higher rate of blood perfusion (Clarke et al. 1996). The extent to which such changes in blood flow and cell development can act to maintain fetal growth and determine later placental function remains to be determined. These alterations in placental development may have a significant effect on placental mass at term as it has been shown that a loss of body weight or condition score in early-mid gestation, followed by adequate nutrition in late gestation can result in a greater (McCrabb et al. 1991) or smaller placental mass (Clarke et al. 1997), depending in part on maternal body weight.

\section{Maternal and fetal responses to nutrient restriction}

The lower maternal plasma thyroid hormone concentrations associated with nutrient restriction are likely to be a direct response to lower energy intake (Dauncey, 1990), but this was not accompanied by any significant increase in plasma NEFA or 3-hydroxybutyrate concentrations and all ewes remained normoglycaemic. These results suggest that any effect of nutrient restriction on other metabolic hormones such as insulin or growth hormone will be minimal as these only alter following large fluctuations in plasma nutrient concentrations (Bauer et al. 1995). The placenta is known to be influenced by a variety of maternal hormones, including thyroid hormones, that have been shown in vitro to stimulate production of placental hormones from human placenta (Maruo et al. 1991). In addition the placenta can modulate the maternal and hormonal environments due to its ability to either secrete inhibitory factors (e.g. prostaglandin $E_{2}$, adenosine; Gunn \& Gluckman, 1995) or metabolize stimulatory hormones (e.g. thyroid hormones, noradrenaline; Roti et al. 1981; Bzoskie et al. 1995). The observation of a higher plasma $T_{3}$ concentration in umbilical cord plasma taken at post-mortem suggests that fetal thyroid development was promoted and/or the placenta's ability to monodeiodinate $T_{3}$ was reduced. Any change in fetal thyroid status following maternal nutrient restriction may explain why brain weight was altered, as development of the brain is known to be dependent on normal thyroid hormone secretion (Nunez, 1984). The extent to which any alterations in placental and fetal development are linked to lower maternal plasma thyroid hormones concentrations directly, rather than via reduced energy intake and concomitant reductions in other anabolic hormones such as insulin-like growth factor-1 (Ma et al. 1992) remains to be determined.

Body condition score did decline in nutrient-restricted ewes although this was not accompanied by a decline in body weight, which remained similar to controls. Clearly, detailed examination of maternal body composition following nutrient restriction in early to mid gestation is required to determine if this is accompanied by appreciable loss of maternal fat stores. The observation in the present study that nutrient restriction was associated with a smaller rather than a larger placenta as observed when ewes are under-fed and lose weight (McCrabb et al. 1991), suggests that major factors determining placental, and possibly fetal responses to nutrient restriction are both maternal body weight (McCrabb et al. 1992; Robinson et al. 1994) and body conformation (Clarke et al. 1997).

In conclusion, maternal nutrient restriction over the period of rapid placental growth is associated with a smaller placental mass. The extent to which this could subsequently compromise fetal development in late gestation remains to be determined.

\section{Acknowledgements}

The research was funded by The Wellcome Trust, and L. Heasman was supported by a Ministry of Agriculture, Fisheries and Food studentship.

\section{References}

Agricultural and Food Research Council Technical Committee on Responses to Nutrients (1992) Energy and Protein Requirements of Ruminants. Report no. 9, pp. 812-815. Wallingford: CAB INTERNATIONAL.

Alexander G (1964) Studies on the placenta of the sheep (Ovis aries L) placental size. Journal of Reproduction and Fertility 7 , 289-305.

Bauer MK, Breier BH, Harding JE, Veldhuis JD \& Gluckman PD (1995) The fetal somatotropic axis during long term maternal undernutrition in sheep: evidence for nutritional regulation in utero. Endocrinology 136, 1250-1257.

Bzoskie L, Blount L, Kashiwai K, Tseng Y-T, Hay WW \& Padbury JF (1995) Placental norepinephrine clearance: in vivo measurement and physiological role. American Journal of Physiology 269, E145-E149.

Clarke L, Bird JA, Lomax MA \& Symonds ME (1996) Effect of $\beta_{3}$-adrenergic agonist (Zeneca D7114) on thermoregulation in near-term lambs delivered by Cesarean section. Pediatric Research 40, 330-336.

Clarke L, Darby CJ, Lomax MA \& Symonds ME (1994) Effect of ambient temperature during $1 \mathrm{st}$ day of life on thermoregulation in lambs delivered by Cesarean section. Journal of Applied Physiology 76, 1481-1488.

Clarke L, Yakubu DP \& Symonds ME (1997) Influence of maternal body weight on size, conformation and survival of newborn lambs. Reproduction, Fertility and Development 9 , 509-514.

Dauncey MJ (1990) Thyroid hormones and thermogenesis. Proceedings of the Nutrition Society 49, 203-215.

Ehrhardt RA \& Bell AW (1995) Growth and metabolism of the ovine placenta during mid-gestation. Placenta 16, 727-741.

Gunn T \& Gluckman PD (1995) Perinatal thermogenesis. Early Human Development 42, 169-183.

Harding JE, Jones CT \& Robinson JS (1985) Studies on experimental growth retardation in sheep. The effects of a small placenta in restricting transport to and growth of the fetus. Journal of Developmental Physiology 7, 453-457.

Hinegardner RT (1971) An improved fluorometric assay for DNA. Analytical Biochemistry 39, 197-201.

Lowry OH, Rosebrough NJ, Farr AL \& Randall RJ (1951) Protein measurement with the Folin reagent. Journal of Biological Chemistry 193, 141-150.

Ma L, Burton KA, Saunders JC \& Dauncey MJ (1992) Thermal and nutritional influences on tissue levels of insulin-like growth 
factor mRNA and peptide. Journal of Thermal Biology 17, 89 95.

McCrabb GJ, Egan AR \& Hosking BJ (1991) Maternal undernutrition during mid-pregnancy in sheep. Placental size and its relation to calcium transfer during late pregnancy. British Journal of Nutrition 65, 157-168.

McCrabb GJ, Egan AR \& Hosking BJ (1992) Maternal undernutrition during mid-pregnancy in sheep: variable effects on placental growth. Joumal of Agricultural Science, Cambridge 118, $127-132$.

Maruo T, Matsuo H \& Mochizuki M (1991) Thyroid hormone as a biological amplifier of differentiated trophoblast function in early pregnancy. Acta Endocrinologica 127, 118-122.

Nunez J (1984) Effects of thyroid hormones during brain differentiation. Molecular Cellular Endocrinology 37, 125-132.

Owens JA, Owens PC \& Robinson JS (1995) Experimental restriction of fetal growth. In Fetus and Neonate, vol. 3 . Growth, pp. 139-175 [MA Hanson, JAD Spencer and CH Rodeck, editors]. Cambridge University Press: Cambridge.

Robinson JJ (1990). Nutrition in the reproduction of farm animals. Nutrition Research Reviews 3, 253-276.

Robinson JJ, McDonald I, Fraser C \& Crofts RMJ (1977) Studies on reproduction in prolific ewes. 1. Growth of the conceptus, Journal of Agricultural Science, Cambridge 88, 539-552.
Robinson JS, Owens JA, DeBarro T, Lok F \& Chidzanja S (1994) Maternal nutrition and fetal growth. In Early Fetal Growth and Development, pp. 317-329 [RHT Ward, SK Smith and D Donnai, editors]. London: RCOG Press.

Roti E, Fang SL, Green K, Emerson CH \& Braverman LE (1981) Human placenta is an active site of thyroxine and $3,3^{\prime}, 5-$ triiodothyronine tyrosol ring deiodination. Journal of Clinical Endocrinology and Metabolism 53, 498-501.

Russel AJF, Doney JM \& Gunn RG (1969) Subjective assessment of body fat in live sheep. Journal of Agricultural Science, Cambridge 72, 451-454.

Schneider H (1996) Ontogenic changes in the nutritive function of the placenta. Placenta 17, 15-26.

Symonds ME (1995) Pregnancy, parturition and neonatal development - interactions between nutrition and thyroid hormones. Proceedings of the Nutrition Society 54, 329343.

Symonds ME, Bryant MJ \& Lomax MA (1986) The effect of shearing on the energy metabolism of the pregnant ewe. British Journal of Nutrition 56, 635-643.

Vatnick I, Schoknecht PA, Darrigrand R \& Bell AW (1991) Growth and metabolism of the placenta after unilateral fetectomy in twin pregnant ewes. Journal of Developmental Physiology 15, 351-356. 